\title{
A comparison of schedule-induced attack in White King and White Carneaux pigeons
}

\author{
THOMAS A. LOONEY and JOHN T. McCLURE \\ Lynchburg College, Lynchburg, Virginia 24501
}

\begin{abstract}
The following conditions were presented to 12 White King and 12 White Carneaux pigeons: a fixed-time (FT) 90-sec food schedule, no food, and a return to the FT schedule. Scheduleinduced attack against a pictorial target was sustained throughout the experiment for 10 White Kings and 4 White Carneaux. These results are consistent with other studies using either White Kings or White Carneaux with a pictorial target and strongly support the conclusion that White King is the more aggressive strain.
\end{abstract}

Studies of schedule-induced attack in pigeons have focused primarily on the schedule conditions or targetrelated variables necessary to engender and sustain at tack. Hence, relatively little is known about the effects of various subject characteristics on this behavior (see Looney \& Cohen, in press, for a review). For example, Azrin, Hutchinson, and Hake (1966) reported no differences in the aggressive behavior of White Carneaux, Silver Kings, and White Kings. In contrast, Looney, Cohen, and Yoburn (1976) have suggested that White Kings may be more aggressive than White Carneaux. The purpose of the present study was to further explore this issue.

In comparing schedule-induced attack in different strains, rules must obviously be established to determine whether induced attack has in fact occurred. The traditional method for demonstrating that attack is induced is to show that more attack occurs during exposure to intermittent reinforcement than during a no-schedule condition. Although within-subjects comparisons are generally made, this need not be the case. Yoburn, Cohen, and Campagnoni (in press) used a betweengroups comparison. They reported results from groups given either intermittent food or no food in experimental sessions of equal duration. All pigeons were exposed to 25 sessions. A pictorial target was present during the last 10 of these sessions. Although three of the subjects in the no-food group contacted the target, none of them had a daily rate exceeding .50 responses/ min. It should be noted that the target used by Yoburn et al. is essentially identical to that used in the present experiment. Hence, a criterion of .50 responses/min, as well as the traditional within-subjects comparison of schedule and no-schedule sessions, was used to determine whether attack was induced and sustained in the present study.

This research was supported in part by USPHS Grant R03MH31172-01 to Lynchburg College. The authors thank M. A. Looney for her helpful comments.

\section{METHOD}

Subjects

Twenty-four experimentally naive 1-year-old pigeons from Palmetto Pigeon Plant (Sumter, South Carolina) were maintained at approximately $75 \%$ of their free-feeding body weights. Of the 24 pigeons, 12 were White Kings and 12 were White Carneaux. They were visually isolated from each other in individual home cages under $16 \mathrm{~h}$ of light followed by $8 \mathrm{~h}$ of darkness. Water and health grit were continuously available. Wing and tail feathers were kept short by periodic trimmings.

\section{Apparatus}

Two operant pigeon chambers (35.6 $35.6 \times 34.3 \mathrm{~cm}$ high) were located in separate rooms. Response keys were inoperative and never illuminated. The food hopper could be made available through a $5.0 \times 5.7 \mathrm{~cm}$ opening centered on the intelligence panel $8.9 \mathrm{~cm}$ above the floor.

The target image was provided by a rear-view projection unit described in detail by Cohen, Yoburn, and Looney (1976). The colored image of a conspecific was very similar in appearance to Pictorial Target B employed by Looney et al. (1976). It was projected onto a Polocoat plastic screen located behind an $11.4 \mathrm{x}$ $15.2 \mathrm{~cm}$ opening centered on the rear wall $8.9 \mathrm{~cm}$ from the floor. To prevent damage to the screen, it was covered with a piece of Con-Tact brand transparent self-adhesive plastic. An attack response was recorded when a force of at least $.1 \mathrm{~N}$ was applied to the target screen. The only chamber illumination was provided by the projected image. A blower provided ventilation and masked extraneous sounds. Standard electromechanical control and recording devices were located in an adjacent room.

\section{Procedure}

Six subjects of each strain were arbitrarily assigned to each chamber. During the first two sessions, all subjects were trained to eat reliably from the food hopper. Subjects were then exposed to a fixed-time (FT) 90 -sec food schedule. The first food presentation occurred with the introduction of the subject into the experimental chamber. Thereafter, food presentation was scheduled to occur after 90 sec. A protective contingency delayed food delivery until no attack had occurred for 10 sec. Sessions ended with the 11 th 10 -sec hopper presentation. The target was first presented during Session 26 of the FT 90-sec schedule condition. Once the target was introduced, it remained thereafter. After 20 sessions under the FT schedule condition with the target, subjects were exposed to a no-food condition for 10 sessions, followed by a return to the FT schedule condition for 15 sessions. During the no-food condition, subjects were placed in the chamber for $20 \mathrm{~min}$. Sessions were conducted daily throughout the experiment. 


\section{RESULTS AND DISCUSSION}

All of the White Kings and 11 of the White Carneaux had over .50 responses/min in at least one session. However, the two groups differed markedly with regard to the length of time that this rate was sustained. Ten White Kings had a median of over .50 responses $/ \mathrm{min}$ during the last five sessions of each exposure to the FT schedule. In contrast, seven White Carneaux met this criterion during the first exposure to the FT condition, and only four of these subjects met the criterion during the second exposure. In no case did a subject make more attacks in the last five sessions of the no-schedule condition than in the last five sessions of either exposure to the FT schedule. Thus, 10 White Kings and 4 White Carneaux showed sustained schedule-induced attack for the duration of this experiment.

The present findings are consistent with several studies that have used either White Kings or White Carneaux and a pictorial target. For example, Looney and Dove (1978) found that 9 of 12 White Kings exposed to a procedure very similar to that employed in the present study showed sustained attack. The percentage of White Kings showing sustained attack has been even greater in other studies employing FT schedules (Yoburn \& Cohen, 1979; Yoburn et al., in press; Flory \& Smith, Note 1).

On the other hand, studies using White Carneaux exposed to pictorial targets have reported that very few subjects exhibit sustained attack. Looney and Cohen (1974) found that only two of six subjects exposed to fixed-interval (FI) schedules exhibited sustained attack. Other investigators employing FT and FI schedules have reported smaller percentages of attackers (Flory \& Ellis, 1973; Rashotte, Griffin, \& Katz, Note 2).

A variety of factors differed across the studies cited, and some of these, such as characteristics of the pictorial target and time of target introduction, can undoubtedly influence attack probability (Looney et al., 1976). However, the overall consistency of results from these studies and the similarity with the results of the present experiment strongly support the conclusion that White Kings are more aggressive than White Carneaux. Moreover, this difference does not appear to be restricted to schedule-induced attack. Pigeon breeders at Palmetto Pigeon Plant report that in the reproductive siutation, White Kings are more aggressive toward other pigeons and humans than are White Carneaux.

The fact that not all subjects attack inanimate targets is often seen to be a major disadvantage. In some cases, however, this may actually be an advantage. A pictorial target can provide a more sensitive index of aggressiveness than does a live target when the percentage of subjects that show sustained attack is the dependent variable of primary interest. For example, the differences found between strains in this study and between the attack-inducing power of different intermittent schedules reported by Yoburn et al. (in press) might well have been obscured if a live target had been used (Looney \& Cohen, in press).

\section{REFERENCE NOTES}

1. Flory, R. K., \& Smith, C. T. The effect of limited target availability on schedule-induced attack. Paper presented at the annual meeting of the Psychonomic Society, St. Louis, 1980.

2. Rashotte, M. E., Griffin, R. W., \& Katz, N. H. Differential control of pigeons' aggressive behavior by pigeon and nonpigeon images presented during intermittent feeding. Paper presented at the annual meeting of the Psychonomic Society, St. Louis, 1973.

\section{REFERENCES}

Azrin, N. H., Hutchinson, R. R., \& Hake, D. F. Extinctioninduced aggression. Journal of the Experimental Analysis of Behavior, 1966, 9, 191-204.

Cohen, P. S., Yoburn, B. C., \& Looney, T. A. An inexpensive random-access projector for rapid presentation of pictorial images. Journal of the Experimental Analysis of Behavior, 1976, 26, 131-134.

FLORY, R. K., \& ElLis, B. B. Schedule-induced aggression against a slide-image target. Bulletin of the Psychonomic Society, 1973, 2, 287-290.

Looney, T. A., \& Cohen, P. S. Pictorial target control of schedule-induced attack in White Carneaux pigeons. Journal of the Experimental Analysis of Behavior, 1974, 21, 571-584.

Looney, T. A., \& Cohen, P. S. Aggression induced by intermittent positive reinforcement. Neuroscience and Biobehavioral Reviews, in press.

Looney, T. A., Cohen, P. S., \& Yoburn, B. C. Variables affecting establishment of schedule-induced attack on pictorial targets in White King pigeons. Journal of the Experimental Analysis of Behavior, 1976, 26, 349-360.

Looney, T. A., \& Dove, L. D. Schedule-induced attack as a function of length of exposure to a fixed-time 90 -sec schedule. Bulletin of the Psychonomic Society, 1978, 12, 320-322.

Yoburn, B. C., \& Cohen, P. S. Assessment of attack and drinking in White King pigeons on response-independent food schedules. Journal of the Experimental Analysis of Behavior, 1979, 31, 91-101.

Yoburn, B. C., Cohen, P. S., \& Campagnoni, F. R. The role of intermittent food in the induction of attack in pigeons. Journal of the Experimental Analysis of Behavior, in press.

(Received for publication June 29, 1981.) 